\title{
Largely tunable dispersion chirped polymer FBG
}

Min, Rui; Korganbayev, Sanzhar; Molardi, Carlo; Broadway, Christian; Hu, Xuehao; Caucheteur, Christophe; Bang, Ole; Antunes, Paulo; Tosi, Daniele; Marques, Carlos

Total number of authors:

11

Published in:

Optics Letters

Link to article, DOI:

10.1364/OL.43.005106

Publication date:

2018

Document Version

Publisher's PDF, also known as Version of record

Link back to DTU Orbit

Citation $(A P A)$ :

Min, R., Korganbayev, S., Molardi, C., Broadway, C., Hu, X., Caucheteur, C., Bang, O., Antunes, P., Tosi, D., Marques, C., \& Ortega, B. (2018). Largely tunable dispersion chirped polymer FBG. Optics Letters, 43(20), 5106-5109. https://doi.org/10.1364/OL.43.005106

\section{General rights}

Copyright and moral rights for the publications made accessible in the public portal are retained by the authors and/or other copyright owners and it is a condition of accessing publications that users recognise and abide by the legal requirements associated with these rights.

- Users may download and print one copy of any publication from the public portal for the purpose of private study or research.

- You may not further distribute the material or use it for any profit-making activity or commercial gain

- You may freely distribute the URL identifying the publication in the public portal 


\title{
Largely tunable dispersion chirped polymer FBG
}

\author{
Rui Min, ${ }^{1, *}$ Sanzhar Korganbayev, ${ }^{2}$ Carlo Molardi, ${ }^{3}$ Christian Broadway, ${ }^{4}$ (i) \\ Xuehao Hu, ${ }^{4}$ Christophe Caucheteur, ${ }^{4}$ Ole Bang, ${ }^{5}$ Paulo Antunes, ${ }^{6}$ (i) Daniele Tosi, ${ }^{2,3}$ \\ Carlos Marques, ${ }^{6}$ (1) and Beatriz Ortega ${ }^{1}$ \\ ${ }^{1}$ ITEAM Research Institute, Universitat Politècnica de València, 46022 Valencia, Spain \\ ${ }^{2}$ National Laboratory Astana, Laboratory of Biosensors and Bioinstruments, 010000 Astana, Kazakhstan \\ ${ }^{3}$ Department of Electronic and Computer Engineering, Nazarbayev University, 010000 Astana, Kazakhstan \\ ${ }^{4}$ Electromagnetism and Telecommunication Department, University of Mons, 7000 Mons, Belgium \\ ${ }^{5}$ DTU Fotonik, Department of Photonics Engineering, Technical University of Denmark, Denmark and SHUTE Sensing Solutions IVS, Denmark \\ ${ }^{6}$ Instituto de Telecomunicações, and I3N \& Physics Department, Universidade de Aveiro, Campus Universitário de Santiago, \\ 3810-193 Aveiro, Portugal \\ *Corresponding author: rumi@doctor.upv.es
}

Received 24 July 2018; revised 21 September 2018; accepted 21 September 2018; posted 24 September 2018 (Doc. ID 340432); published 12 October 2018

\begin{abstract}
We demonstrate a largely tunable dispersion fiber Bragg grating (FBG) inscribed in a microstructured polymer optical fiber (mPOF). The bandwidth of the chirped FBG (CFBG) was achieved from 0.11 to $4.86 \mathrm{~nm}$, which corresponds to a tunable dispersion range from 513.6 to $11.15 \mathrm{ps} / \mathrm{nm}$. Furthermore, thermal sensitivity is used to compensate for the wavelength shift due to the applied strain. These results demonstrate that a CFBG in a POF is a promising technology for future optical systems. @2018 Optical Society of America
\end{abstract}

https://doi.org/10.1364/OL.43.005106

Chirped fiber Bragg gratings (CFBGs) in silica fibers are attractive components that have been implemented for a variety of applications, such as long distance dispersion compensation [1], optoelectronic oscillators [2], mode-locked fiber lasers [3], and accelerometer [4] or biomedical sensing [5]. Furthermore, microwave photonics is also a promising application area where dispersive elements are required, which includes beamforming for phased array antennas [6], signal generation [7], and reconfigurable transversal filters [8]. Indeed, CFBGs based on silica fibers are a very mature technology, and several techniques have been demonstrated for fabrication and tuning, such as temperature gradient [9], strain gradient [10], varying the period the grating [11], and tuning with ferrofluidic defects in a microstructured optical fiber [12]. However, polymer optical fibers (POFs) show higher thermooptic coefficient, larger elongation before breakage and lower Young's modulus compared with silica fiber. Accordingly, a broader tuning range under temperature and strain, easy handling due to its low stiffness and lower installation costs are some of their main advantages [13], besides its biocompatibility. During the last decade, the use of a POF has been increasing for short reach applications, such as home networks
$[14,15]$ and low-cost interconnects in datacenters [16] or sensors [13], which leads to the current growing interest in novel fiber wavelength sensitive components.

Since the first fiber Bragg grating (FBG) in a POF was reported in 1999 [17], FBGs in a POF have become attractive devices for optical communication and sensing. Some examples include phase-shifted FBGs [18], tilted FBGs [19], and FBGs in low loss cyclic transparent amorphous fluoropolymers (CYTOP) POFs [20,21], as reported in recent literature. CFBGs in a POF were theoretically proposed for a tunable dispersion in 2005 [22] by applying both the strain and temperature, showing a potential large dispersion tuning range from 110 to $2400 \mathrm{ps} / \mathrm{nm}$. However, experimentally, the first CFBG in a POF was successfully fabricated by using a chirped phase mask in 2017 [23]; in addition, CFBGs have been recently fabricated in a POF at $850 \mathrm{~nm}$ by using a uniform phase mask and non-uniform tapered fibers [24].

In this Letter, we present, to the best of our knowledge, the first dispersion experimental demonstration of largely tunable dispersive FBGs in a POF, where a dispersion range from positive 11.15 to $513.6 \mathrm{ps} / \mathrm{nm}$ and negative 490.60 to $15.90 \mathrm{ps} / \mathrm{nm}$ has been achieved; therefore, CFBGs in a POF are confirmed as being very promising dispersive devices for a variety of applications.

The use of tapered silica fibers in 1996 [25] allowed the demonstration of a variable group delay slope of the CFBG by applying different strain values. Liu et al. [22] provided simulation results for a similar approach in polymer fibers. In this Letter, we present a tunable dispersion CFBG inscribed in an endlessly single-mode benzyl dimethyl ketal-doped poly (methyl methacrylate) (PMMA) microstructured POF (mPOF) [26], which was fabricated in DTU Fotonik by using the center hole doping technique. In order to remove any residual stress of the fiber from the drawing process, the fiber was pre-annealed at $80^{\circ} \mathrm{C}$ for $24 \mathrm{~h}$. A $20 \mathrm{~cm}$ long fiber sample was connected to a ferrule, cleaved with a portable cleaver [27], 
(a)

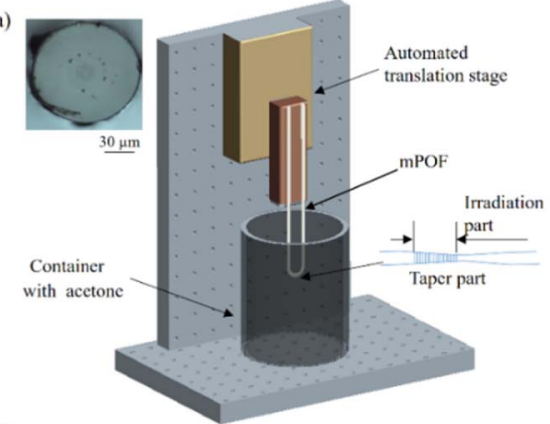

(b)

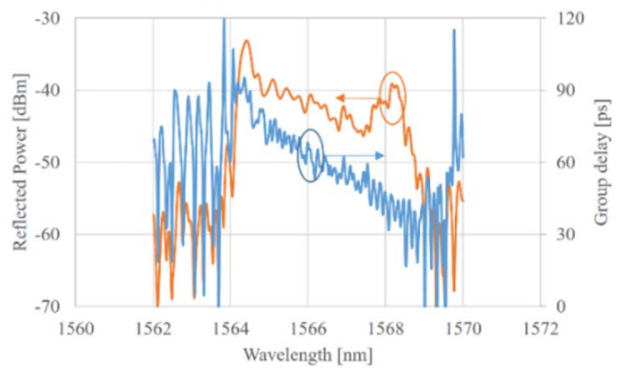

Fig. 1. (a) Taper setup for a mPOF; inset: the end face of a mPOF. (b) Reflected spectral power and the group delay after the fabrication and strain are released.

and polished with sandpaper to enhance the end face quality. As explained in Ref. [28], acetone can be employed to obtain POF etching. In our experiment, prior to the inscription process, the fiber section was immersed in acetone, while a constant speed automatic translation stage was used to shift the fiber during the etching process, resulting in a non-uniform etching time for different fiber sections. Consequently, a linear tapered section, as shown in Fig. 1(a), is obtained with high reliability and repeatability; the tapered fiber diameter has been measured along the taper of two points separated by $10 \mathrm{~mm}$ as 65 and $55 \mu \mathrm{m}$, leading to a linear taper profile of $1 \mu \mathrm{m} / \mathrm{mm}$. The tapered fiber was subjected to a $1 \%$ strain during exposure by a single pulse (with duration of $15 \mathrm{~ns}$ ) with $2.5 \mathrm{~mJ}$ energy from a $248 \mathrm{~nm}$ $\mathrm{KrF}$ laser at $248 \mathrm{~nm}$ where a $10 \mathrm{~mm}$ long uniform phase mask of $1064 \mathrm{~nm}$ period was used, delivering a $10 \mathrm{~mm}$ long CFBG. The laser beam profile was measured as a rectangular Tophat function of $6.0 \mathrm{~mm}^{2} \times 1.5 \mathrm{~mm}^{2}$ size and $2 \mathrm{mrad}^{2} \times 1 \mathrm{mrad}^{2}$, and a slit of $10 \mathrm{~mm}$ width sets the length of the grating. It was focused onto the fiber core utilizing a plano-convex cylindrical lens (Newport CSX200AR.10) with a focal length of $20 \mathrm{~cm}$. Additional details can be found in Ref. [24].

Given that microstructuring is typically known to scatter about $20 \%$ of the incident light during a successful inscription, some inhomogeneities may exist in the fiber refractive index profile. In symmetric microstructured fibers, inscription is successful provided no capillaries are in the light path of the inscription laser beam. Oppositely, in the worst case, the FBG profile is affected, and the fiber is directionally sensitive. However, work by Broadway et al. has shown that for He-Cd inscription of a PMMA mPOF, lateral directivity appears mechanically homogeneous over a $20 \mathrm{deg}$ arc, even at pressures as low as $1 \mathrm{kPa}$ [29]. An optical backscatter reflectometer (LUNA 4600 ) with a wavelength resolution of $33 \mathrm{pm}$ was used to measure the reflected power and group delay. Figure 1(b) shows

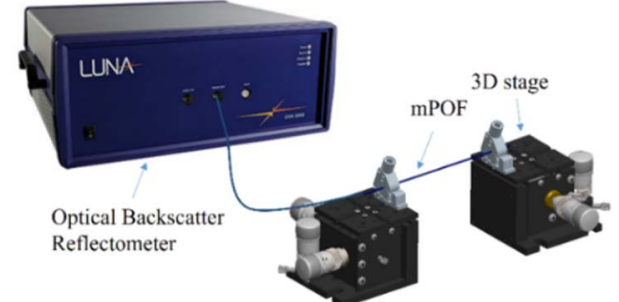

Fig. 2. Experimental setup for strain measurements.

the reflected spectral power and the group delay of the fabricated CFBG after the strain release, performing similarly to taper a CFBG in silica fibers [30]. The maximum bandwidth was $4.86 \mathrm{~nm}$, corresponding to a chirp of $0.486 \mathrm{~nm} / \mathrm{mm}$ and a dispersion value around $11.15 \mathrm{ps} / \mathrm{nm}$.

A $5 \mathrm{~cm}$ long POF, including a $1 \mathrm{~cm}$ long CFBG, was subjected between two fiber clamps (Thorlabs HF001) fixed on the translation stage, as shown in Fig. 2, which shifts every $10 \mu \mathrm{m}$ step $(0.005 \%)$. Figures $3(\mathrm{a})$ and 3 (b) show the strain dependence of the reflected spectral power and group delay of the grating. It is clearly shown that the chirped grating response strongly varies with the applied strain. The slope of the group delay versus the wavelength (i.e., a grating dispersion) varies according to the bandwidth change, since the maximum grating delay is given by the grating length. The group delay shows a
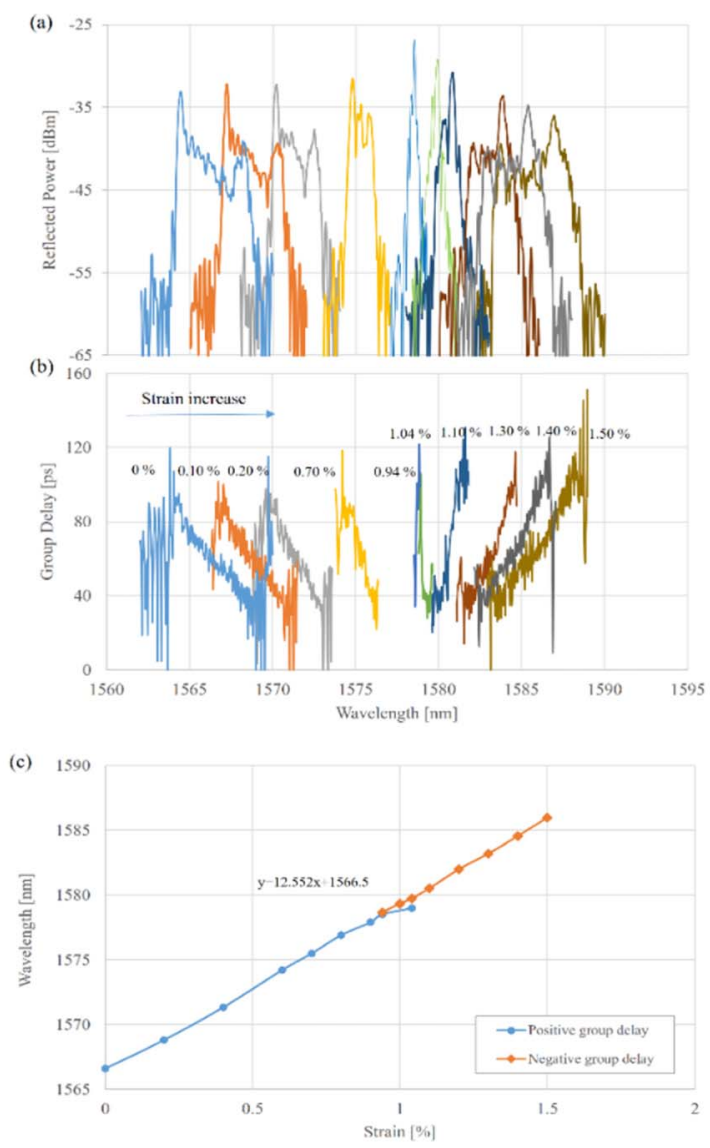

Fig. 3. (a) Reflected spectrum versus the strain. (b) Group delay versus the strain. (c) Central wavelength shift versus the strain. 
positive slope for strain levels higher than $1 \%$ and a negative slope when the strain decreases from the value employed during the grating inscription. The reason for that is due to the stressoptic effect, which is opposite the lengthening effect [30], and a chirp cancellation occurs. As expected, the central wavelength of the grating shifts to longer wavelengths when the strain increases. Figure 3(c) shows a strain sensitivity of $1.26 \pm 0.02 \mathrm{pm} / \mu \varepsilon$, similar to a uniform POFBG in the same material at $1530 \mathrm{~nm}$ $(\sim 1.3 \mathrm{pm} / \mu \varepsilon)$ [31].

Figure 4 shows the bandwidth dependence and the dispersion with the applied strain. In Fig. 4(a), the negative slope region shows a bandwidth decrease with a strain of $5.01 \mathrm{~nm} / \%$, whereas higher values of a strain than $1 \%$ lead to an increase of $8.71 \mathrm{~nm} / \%$. Figure $4(\mathrm{~b})$ shows the dependence of the grating dispersion on the strain, where a dispersion increase from 11.15 to $513.60 \mathrm{ps} / \mathrm{nm}$ is achieved by increasing the strain up to $1.04 \%$. A negative dispersion of $490.60 \mathrm{ps} / \mathrm{nm}$ is measured for strain values of $0.94 \%$, and it decreases to $15.90 \mathrm{ps} / \mathrm{nm}$ when a $1.5 \%$ strain is applied. During a $0.94 \%-1.04 \%$ strain, two opposite sign dispersions appeared due to the process of the conversion of the group delay slope. Since the grating is inscribed under a $1 \%$ strain, the chirp is caused because of the stress-optic effect (i.e., the strain gradient along the fiber). However, in this case, the grating pitch is not varying over the taper. After release, the chirp due to the stressoptic effect disappears, but another chirp appears due to the different parts of the taper relaxing differently from the initial strain gradient (reversely to the lengthening effect) [30]. Therefore, larger chirps can be created, and the chirped grating can be packaged strain-free [24]. A detailed theory is provided following the analysis of $r$ (radius) and $L$ (fiber length) in chirped gratings using the transfer matrix method [32].

Figure 3(c) shows the central wavelength shift with the applied strain, which we propose to be compensated for with the effect of temperature. Consequently, we characterize the CFBG response between $30^{\circ} \mathrm{C}$ and $52^{\circ} \mathrm{C}$. The grating was placed on a Peltier plate with the temperature maintained by an electronic temperature controller. Figures 5(a) and 5(b)

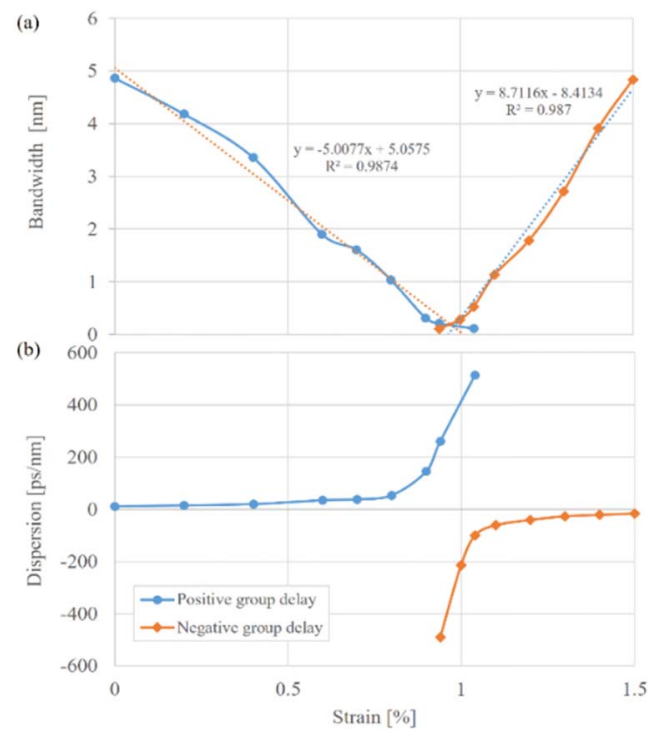

Fig. 4. Characterization of the CFBG response: (a) the bandwidth versus the strain and (b) the dispersion versus the strain.

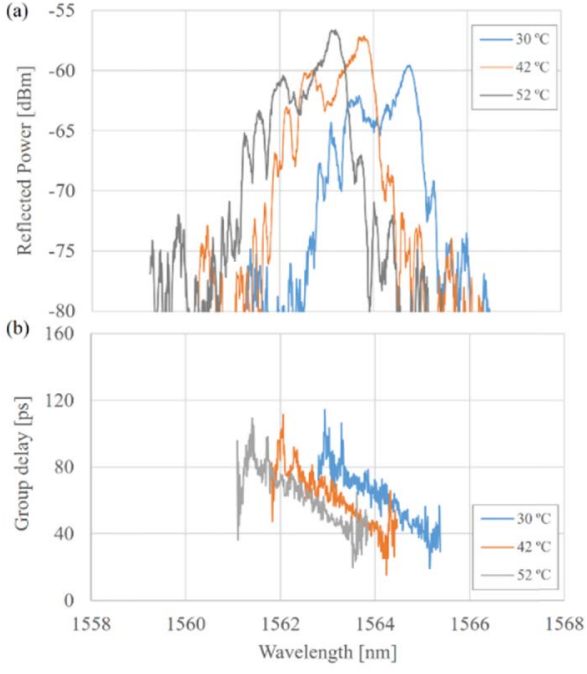

Fig. 5. CFBG response characterization at different temperatures: (a) the reflected spectral power versus the wavelength and (b) the group delay versus the wavelength.

show the obtained reflected spectral power and the group delay measurements. Figure 6 shows a linear dependence of the central wavelength with the temperature, yielding a sensitivity of $0.0719 \mathrm{~nm} /{ }^{\circ} \mathrm{C}$. Therefore, we can conclude that we can achieve a $1.6 \mathrm{~nm}$ tuning range over $22^{\circ} \mathrm{C}$ temperature tuning. Note that this value is larger than the $1.3 \mathrm{~nm}$ achieved in a silica FBG when a $100^{\circ} \mathrm{C}$ temperature change is applied [33] .

Figure 7 shows that the bandwidth and dispersion of the CFBG are stable when the temperature varies in the range of $30^{\circ} \mathrm{C}-52^{\circ} \mathrm{C}$. The dispersion is estimated as $26.2 \pm$ $0.4 \mathrm{ps} / \mathrm{nm}$ and keeps constant within the margin of error. The measured blueshift of the central wavelength with temperature can be employed to compensate for the wavelength shift obtained when an external strain is applied for the sake of dispersion tunability, which makes this dispersion device even more flexible. Figure 4 shows a large range of dispersion, from $145.8 \mathrm{ps} / \mathrm{nm}$ at a $0.9 \%$ strain to $513.6 \mathrm{ps} / \mathrm{nm}$ at a $1.04 \%$ strain, under a central wavelength shift of $1.76 \mathrm{~nm}$.

For example, to offset the center wavelength increase induced by a $0.14 \%$ applied strain, the required temperature rise is $24^{\circ} \mathrm{C}$, which is suitable for the temperature range for POFBG technology. In a silica $\mathrm{FBG}$, the temperature and strain sensitivities are $11.3 \mathrm{pm} /{ }^{\circ} \mathrm{C}$ and $1.06 \mathrm{pm} / \mu \varepsilon$, so a $132^{\circ} \mathrm{C}$ temperature change would be required to compensate for

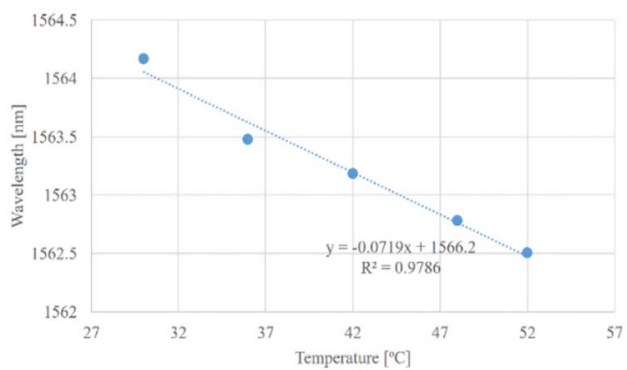

Fig. 6. Linear dependence of the central wavelength under different temperatures. 


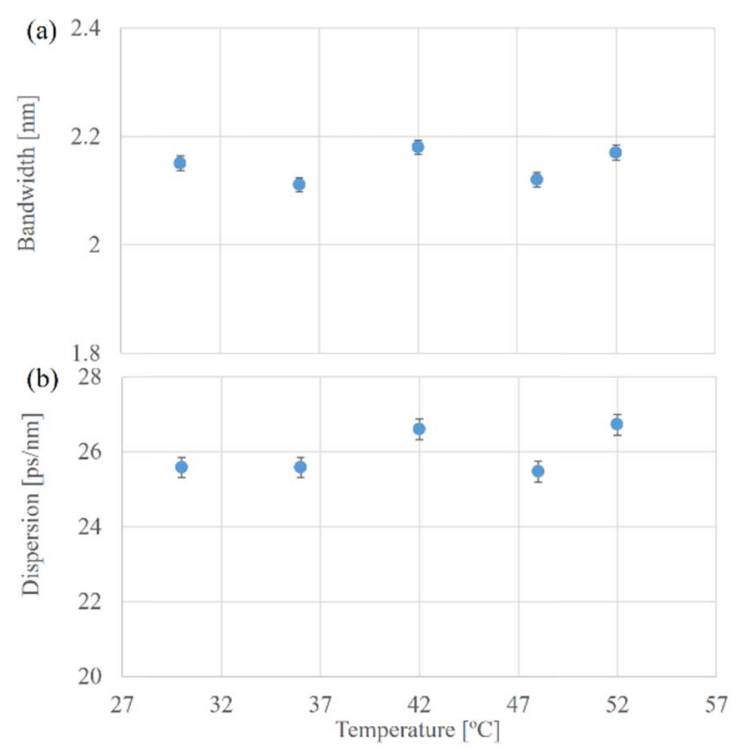

Fig. 7. (a) Bandwidth versus the temperature and the dispersion versus the temperature.

the wavelength shift due to a $0.14 \%$ applied strain, which is not practical for real application [33].

In conclusion, for the first time, to the best of our knowledge, the tunable dispersion of a chirped fiber Bragg grating inscribed in a POF by using a non-uniform tapered fiber technique has been demonstrated. We also propose to employ temperature in order to compensate for the central wavelength shift due to the applied strain, and therefore, promising tunable CFBG devices are presented for future optical systems.

Funding. Fundação para a Ciência e a Tecnologia (FCT) (SFRH/BPD/109458/2015, UID/EEA/50008/2013); Research Excellence Award Programme GVA (PROMETEO 2017/103); Oak Ridge Associated Universities (ORAU) (LIFESTART (2017-2019)); Natural Science Foundation of Heilongjiang Province (F2018026).

Acknowledgment. The authors acknowledge the support of Azat Abdullayev for the strain setup outline. D. Tosi and S. Korganbayev are supported by ORAU.

\section{REFERENCES}

1. P. I. Reyes, N. Litchinitser, M. Sumetsky, and P. S. Westbrook, IEEE Photon. Technol. Lett. 17, 831 (2005).

2. Z. Tang, S. Pan, D. Zhu, R. Guo, Y. Zhao, M. Pan, D. Ben, and J. Yao, IEEE Photon. Technol. Lett. 24, 1487 (2012).

3. X. He, Z. Liu, and D. N. Wang, Opt. Lett. 37, 2394 (2012).

4. W. Zhou, X. Dong, K. Ni, C. C. Chan, and P. Shum, Sens. Actuators A 157, 15 (2010).
5. D. Tosi, E. G. Macchi, M. Gallati, G. Braschi, A. Cigada, S. Rossi, G. Leen, and E. Lewis, Biomed. Opt. Express 5, 1799 (2014).

6. B. Ortega, J. L. Cruz, J. Capmany, M. V. Andrés, and D. Pastor, IEEE Trans. Microwave Theory Tech. 48, 1352 (2000).

7. C. Wang and J. Yao, IEEE Trans. Microwave Theory Tech. 56, 542 (2008).

8. J. Capmany, B. Ortega, and D. Pastor, J. Lightwave Technol. 24, 201 (2006).

9. J. Lauzon, S. Thibault, J. Martin, and F. Ouellette, Opt. Lett. 19, 2027 (1994).

10. P. C. Hill and B. J. Eggleton, Electron. Lett. 30, 1172 (1994).

11. R. Kashyap, P. F. McKee, R. J. Campbell, and D. L. Williams, Electron. Lett. 30, 996 (1994).

12. A. Candiani, W. Margulis, C. Sterner, M. Konstantaki, and S. Pissadakis, Opt. Lett. 36, 2548 (2011).

13. C. A. F. Marques, D. J. Webb, and P. Andre, Opt. Fiber Technol. 36, 144 (2017).

14. H. Yang, S. J. Lee, E. Tangdiongga, C. Okonkwo, H. P. van den Boom, F. Breyer, S. Randel, and A. M. J. Koonen, J. Lightwave Technol. 28, 352 (2010).

15. F. Forni, Y. Shi, N. C. Tran, H. P. A. van den Boom, E. Tangdiongga, and A. M. J. Koonen, J. Lightwave Technol. 36, 3444 (2018).

16. Y. Shao, R. Cao, Y. K. Huang, P. N. Ji, and S. Zhang, Optical Fiber Communication Conference (Optical Society of America, 2012).

17. Z. Xiong, G. D. Peng, B. Wu, and P. L. Chu, IEEE Photon. Technol. Lett. 11, 352 (1999).

18. L. P. Pereira, A. Pospori, M. F. Domingues, P. Antunes, S. Marques, O. Bang, D. J. Webb, and C. Marques, J. Lightwave Technol. 35, 5176 (2017).

19. X. Hu, C. J. Pun, H. Tam, P. Mégret, and C. Caucheteur, Opt. Lett. 39, 6835 (2014)

20. A. Lacraz, M. Polis, A. Theodosiou, C. Koutsides, and K. Kalli, IEEE Photon. Technol. Lett. 27, 693 (2015).

21. R. Min, B. Ortega, A. Leal-Junior, and C. Marques, IEEE Sens. Lett. 2, 5000804 (2018).

22. H. Liu, H. Liu, G. Peng, and T. W. Whitbread, IEEE Photon. Technol. Lett. 17, 411 (2005).

23. C. A. F. Marques, P. Antunes, P. Mergo, D. J. Webb, and P. André, IEEE Photon. Technol. Lett. 29, 500 (2017).

24. R. Min, B. Ortega, and C. Marques, Opt. Express 26, 4411 (2018).

25. J. L. Cruz, L. Dong, S. Barcelos, and L. Reekie, Appl. Opt. 35, 6781 (1996).

26. X. Hu, G. Woyessa, D. Kinet, J. Janting, K. Nielsen, O. Bang, and C. Caucheteur, Opt. Lett. 42, 2209 (2017).

27. D. Sáez-Rodríguez, R. Min, B. Ortega, K. Nielsen, and D. J. Webb, IEEE Photon. Technol. Lett. 28, 2834 (2016).

28. X. Hu, C. F. J. Pun, H. Y. Tam, P. Mégret, and C. Caucheteur, Opt. Express 22, 18807 (2014).

29. C. Broadway, D. Gallego, A. Pospori, M. Zubel, D. J. Webb, K. Sugden, G. Carpintero, and H. Lamela, Proc. SPIE 9886, 98860S (2016).

30. L. Dong, J. L. Cruz, L. Reekie, and J. A. Tucknott, Electron. Lett. 31, 908 (1995).

31. W. Yuan, A. Stefani, M. Bache, T. Jacobesn, B. Rose, N. H. Rasmussen, F. K. Nielsen, S. Andresen, O. B. Sorensen, K. S. Hansen, and O. Bang, Opt. Commun. 284, 176 (2011).

32. T. Erdogan, J. Lightwave Technol. 15, 1277 (1977).

33. B. O. Guan, H. Y. Tam, X. M. Tao, and X. Y. Dong, IEEE Photon. Technol. Lett. 12, 675 (2000). 